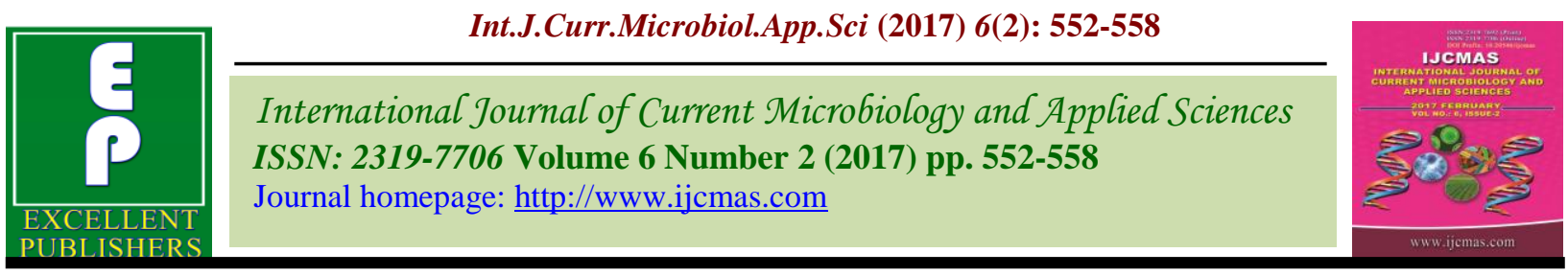

Original Research Article

http://dx.doi.org/10.20546/ijcmas.2017.602.062

\title{
Bioremediation of Toluene using Microbial Consortium Obtained from Industrial Effluent
}

\author{
M.H. Fulekar ${ }^{1}$, T.N. Godambe ${ }^{2}$, Koul Sheetal ${ }^{2}$ and Nair Darshana ${ }^{2}$ \\ ${ }^{1}$ School of Environment and Sustainable Development, Central University of Gujarat, \\ Gandhinagar-482030, India \\ ${ }^{2}$ Environment Biotechnology Lab, Department of Life Sciences, University of Mumbai, \\ Santacruz (E), Mumbai-400 098, India \\ *Corresponding author
}

\section{A B S T R A C T}

\begin{tabular}{|l|}
\hline Ke y w or d s \\
Petrochemical \\
waste, Toluene \\
toxicity, \\
Bioremediation. \\
\hline Article Info \\
\hline $\begin{array}{l}\text { Accepted: } \\
\text { 15 January } 2017 \\
\text { Available Online: } \\
\text { 10 February } 2017\end{array}$ \\
\hline
\end{tabular}

Petrochemical Industry manufacturing petrochemical product-generate waste containing organic compounds. As the toxicity level of most of these compounds is high, there is an increasing demand for remediation of such sites that involves removal of the offending compounds. Bioremediation uses living systems or biological products to biodegrade waste, with the objective being reduction of waste to chemical forms that can be assimilated into natural cycles. In the present study, the use of micro-organism for bioremediation has been carried out. The effluent outlet samples from industrial waste treatment site of the organic compound (toluene) producing industry were collected and assessed for physico-chemical and microbial characterization. Biodegradation studies using microbial consortia obtained after characterization of samples were observed. Bioremediation has proven to be an effective tool in the reduction of environmental contaminants but can rarely restore the affected environment back to its original condition.

\section{Introduction}

Environmental Contamination due to rise in Petrochemical Industry has become a matter of serious concern from the last few decades (Prenafeta-Bold'u1, 2004). Waste effluent generated from the petrochemical Industry consists of highly toxic derivatives of organic compounds like benzene, toluene, xylene and other poly aromatic compounds (Singh, 2009). Among, the mono-aromatic organic compounds, Toluene is widely used as a solvent in printing, paint, adhesive, cosmetic and plastic industry and is classified as a priority pollutant because of its high mobility and toxicity (Martino, 2012). As compared to conventional chemical or physical techniques of remediation which have inherent drawbacks due to high operating cost, difficulty in operation and production of secondary pollutants, Bioremediation which involves the use of naturally occurring microorganisms for biodegradation of toxins presents an alternative, yet better approach for the remediation of Toluene (Janbandhu, 2011).

Toluene is a mono-substituted benzene derivative and features in the list of U. S. EPA priority pollutant; it is a low water-soluble 
constituent of refined petroleum products (e.g., aviation fuels and gasoline) and is a widespread contaminant of groundwater near leaking underground storage tanks, landfills, and other uncontrolled releases of fossil fuels (Karamalidis, 2010). Toluene is a neuro and genotoxin and is known to cause leukoencephalopathy in humans if exposed for a long time (Jacob, 2015).

Owing to the fact, that bacteria can adapt quickly to various conditions, reproduce quickly and have simple growth and storing requirements, in the last two decades, progressive utilization of microorganisms such as bacteria for the removal and biodegradation of petrochemical waste has been observed (Jacob, 2015) (Qi et al., 2007).

The ability of native bacteria at such contaminated sites to degrade toluene has important environmental implications; such organisms are probably the primary determinant of the rate of decontamination in the absence of remediation. If remedial action is taken, such organisms may be an important factor in the remediation scheme (Janbandhu, 2011; Karamalidis, 2010; Harding, 2003; Christofoletti, 2010).

Biodegradation studies involving the degradation of toluene using a pure strain does not represent the actual behaviour of environmental microorganisms during bioremediation in natural toluene contaminated soils, because in nature, bioremediation depends on cooperative metabolic activities of mixed microbial populations. One important advantage of using microbial consortia is that they possess multiple metabolic capacities that increase the efficiency of the bioremediation process (Karamalidis, 2010).

In the present study, samples from various sites of Toluene producing industry were collected followed by their physico-chemical and microbial characterization. The bacterial consortium surviving in the effluent were screened and evaluated for their ability to degrade and mineralize different concentrations of toluene using shake flask method.

The increase in the microbial count and the changes in Chemical Oxygen Demand (COD) and Biological Oxygen Demand (BOD) were monitored and quantified as an indicator for growth and proliferation of microorganisms along the degradation of toluene in the mineral medium. This consortium was checked for their ability to degrade toluene up to $500 \mathrm{ppm}$.

\section{Study area}

One of the prominent toluene manufacturing industry situated at Ratnagiri, Mahad, Maharashtra was selected for collection of effluent sample. The study was conducted for industrial effluent collected from three different sites of the sludge tank viz. inlet, outlet and storage sludge tank.

\section{Materials and Methods}

\section{Chemicals used}

The selected petrochemical compound i.e., toluene- analytical grade, was procured from SD-Fine Chemicals Ltd/Merck, Mumbai. The Nutrient Agar and Nutrient Broth for the culture and isolation of micro-organisms were obtained from HiMedia. Gram staining kit (K001-1KT, HiMedia) was used for isolation and characterization of bacterial cultures. Identification Kit was procured from HiMedia, India for biochemical characterization of selected bacteria. All the other chemicals used were also of analytical grade obtained from SD-Fine Chemicals Ltd/Merck, Mumbai. 


\section{Sample collection}

In the present study, petrochemical industry producing toluene located at Ratnagiri, Mahad, Maharashtra, India was selected for collection of effluent samples. The samples were procured from various sites enlisted: Inlet, Outlet and Stored Sludge respectively for the isolation of potential micro-organisms for degradation of Toluene. All the samples were collected in sterile screw-cap tubes and preserved at $4{ }^{\circ} \mathrm{C}$ in refrigerator.

\section{Physico-chemical and microbial characterization of collected samples}

The collected samples were studied by using APHA standard manual for characterization of waste water samples. The samples were serially diluted 10,000 folds and plated on nutrient agar plates. The colony forming unit (CFU) was determined and also isolation of bacterial isolates was performed. The biochemical assay for the isolates was performed using Enterobactereaceae kit.

\section{Bioremediation of toluene}

Bioremediation experiments were carried out using shake flask bioreactor system at different concentrations of Toluene viz: 50, $100,150,250,500 \mathrm{ppm}$ with the microbial biomass obtained from Toluene industry. The samples were monitored for environmental parameters like $\mathrm{pH}$, Dissolved oxygen, alkalinity, BOD, COD and the degradation was studied using HPLC. Biodegradation was assessed by comparing the disappearance of toluene in the sample compared to the controls over time.

\section{Results and Discussion}

The microbes were cultured in nutrient broth and bacterial colonies were isolated on nutrient agar medium. Five isolates (Table 1) were found to be potential for the degradation of toluene. Biochemical characteristics and Gram staining of the organism were carried out respectively. Out of five, four isolates were gram positive and one gram negative.

The physico-chemical characteristics of the effluent samples from all the three sites were determined. The values of physico-chemical parameters are presented in table 2 .

Successful enrichments for toluene degraders were obtained from the samples collected from three different sites of the sludge tank viz. inlet, outlet, and storage sludge tank. Enrichments positive for toluene degradation were obtained from widely separated and dissimilar habitats. The isolates that were confirmed as pure cultures and they were able to grow on increasing concentrations of 50 to $500 \mathrm{ppm}$ toluene. Successful enrichment and isolation were strongly dependent on the use of relatively low toluene concentrations, typically $50 \mathrm{ppm}$. This strategy was used because our early isolation and enrichment attempts were unsuccessful after extensive effort with $250 \mathrm{ppm}$ and because we had noted a considerable increase in the most probable number estimate of aerobic toluene degraders when the toluene concentration was decreased from 250 to $100 \mathrm{ppm}$ and again when reduced to $50 \mathrm{ppm}$. Thus, we reasoned that toluene toxicity could also be an important factor for successful enrichment and isolation of toluene degraders. Once isolated, the cultures were routinely grown in the medium with $100 \mathrm{ppm}$ of toluene and subcultured further for higher yields.

During biodegradation, the $\mathrm{pH}$ varied between 6.5 and 7.8 (Figure 1), which is desirable since biodegradation rate is highest at near neutral pH (Salleh et al., 2003). With the growth of micro-organisms, variation in $\mathrm{pH}$ from neutral to alkaline was observed, indicating that the degradation is in process. 
Other environmental parameters that could affect bioremediation like temperature and nutrient content were monitored for effective bioremediation.

Dissolved oxygen was observed to decrease during bioremediation, which is a likely indicator of growth and proliferation of microorganisms. The results obtained according to the study of microbial growth for the period of seven days showed a steady growth of microorganisms in 50ppm concentration of toluene within 24hrs. Microbial growth for the concentration of $100 \mathrm{ppm}$ and 150ppm showed increase in the growth of microbes till 4th and 5th day respectively and further stationary phase was observed. In case of the flask containing 250 ppm and 500ppm of toluene a slow growth of microorganism was observed till the period of seven days (Figure 2).

Toluene degradation (Figure 3) results show that in case of $50 \mathrm{ppm}$ toluene degradation started immediately and $100 \%$ degradation of $50 \mathrm{ppm}$ of Toluene was observed over a period of $24 \mathrm{hr}$. Similarly, 100ppm and 150ppm were degraded up to 99.1 and $98.9 \%$ within 72 and 96 hours, respectively. Slow degradation rate was observed for $250 \mathrm{ppm}$ of toluene till 48 hours, and final degradation of $97.6 \%$ was observed at the end of seventh day of study. Higher concentration of $500 \mathrm{ppm}$ toluene was found inhibitory for microbial consortia and fall in the degradation rate was observed for initial 72 hoursof study and $51 \%$ degradation was observed by the end of the 7 th day of bioremediation of toluene.

COD values (Figure 4) were found to be gradually decreasing which indicates that there is degradation of organic compound (Toluene) in the period of 7 days. The decrease in COD (oxygen concentration) with increasing time duration was observed at 50 to $250 \mathrm{ppm}$ of Toluene. There was no significant change observed in COD at the higher concentration of toluene i.e. $500 \mathrm{ppm}$.

Analysis of compounds from the biodegradation of Toluene indicates that in case of $50 \mathrm{ppm}$ of toluene degradation started within few hours and was degraded below detection limit within 24hrs.

Table.1 Bacterial isolates and their Gram's nature

\begin{tabular}{|l|l|l|}
\hline Serial No. & Gram Reaction & Bacterial species \\
\hline Isolate 1 & Gram Negative & Psuedomonas spp \\
\hline Isolate 2 & Gram Positive & Rhodococcus spp \\
\hline Isolate 3 & Gram Positive & Mycobacterium spp \\
\hline Isolate 4 & Gram Positive & Corynebacterium spp \\
\hline Isolate 5 & Gram positive & Bacillus spp \\
\hline
\end{tabular}

Table.2 Physico chemical parameters of the effluent samples

\begin{tabular}{|l|l|l|l|}
\hline Parameters & Inlet & Outlet & Storage Sludge \\
\hline $\mathrm{pH}$ & 7.9 & 7.4 & 7.2 \\
\hline Alkalinity & 300 & 230 & 180 \\
\hline $\mathrm{DO}(\mathrm{mg} / \mathrm{l})$ & 6.9 & 5.7 & 5.2 \\
\hline $\mathrm{BOD}(\mathrm{mg} / \mathrm{l})$ & 62.8 & 33.3 & 26 \\
\hline $\mathrm{COD}(\mathrm{mg} / \mathrm{l})$ & 120 & 66 & 46 \\
\hline
\end{tabular}


Fig.1 pH variation during bioremediation

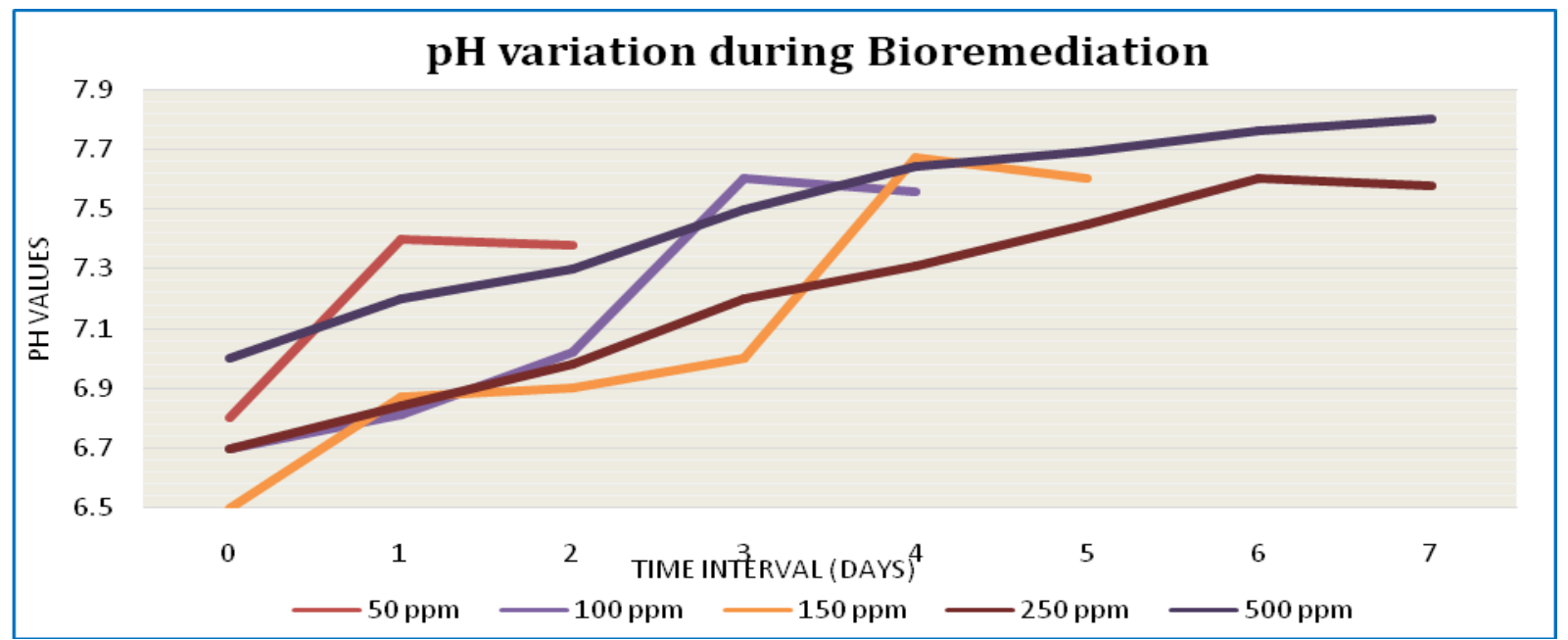

Fig.2 Microbial growth during degradation study

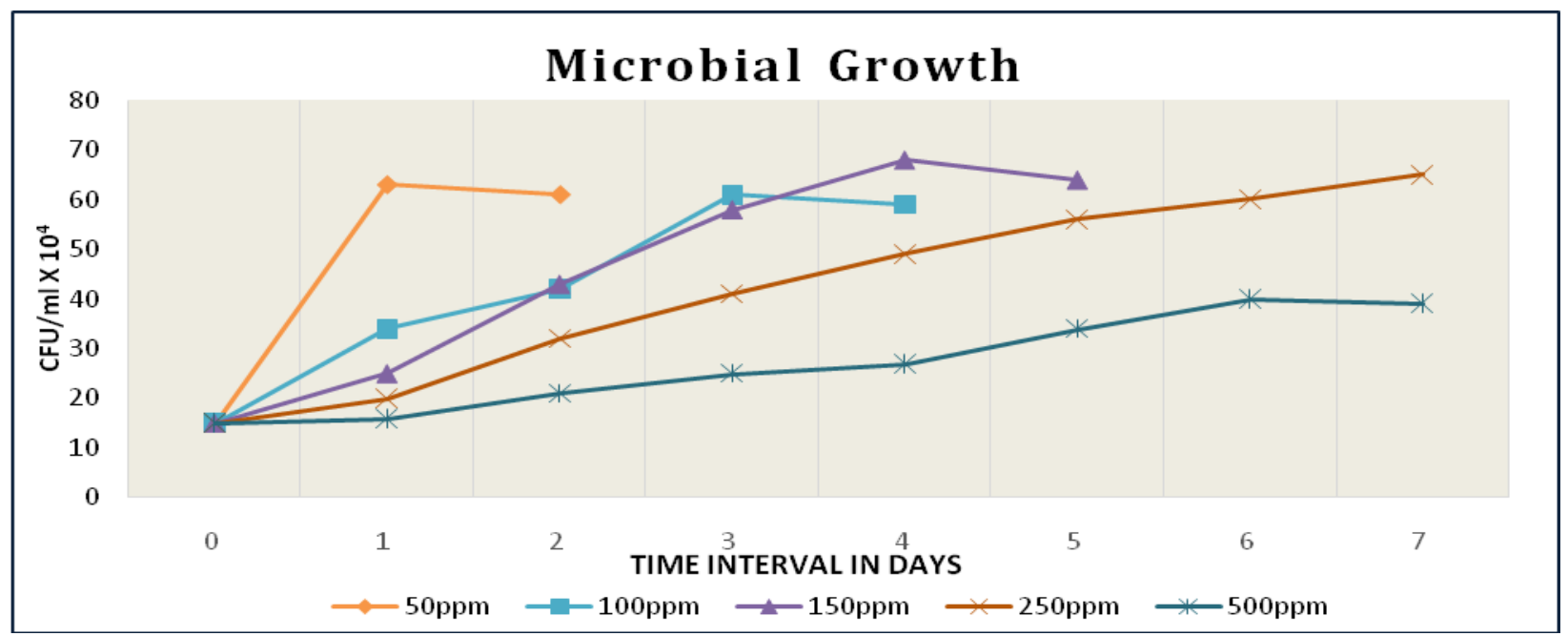

Fig.3 Degradation study of toluene

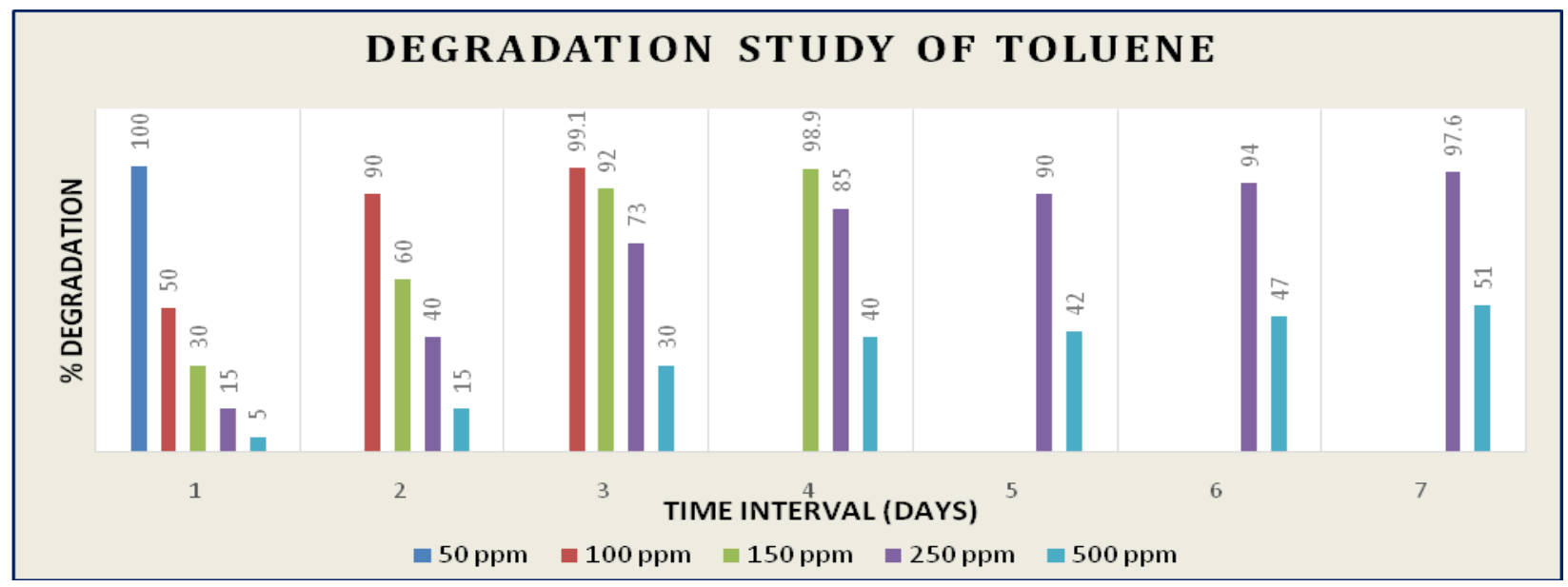


Fig.4 Chemical oxygen demand during bioremediation

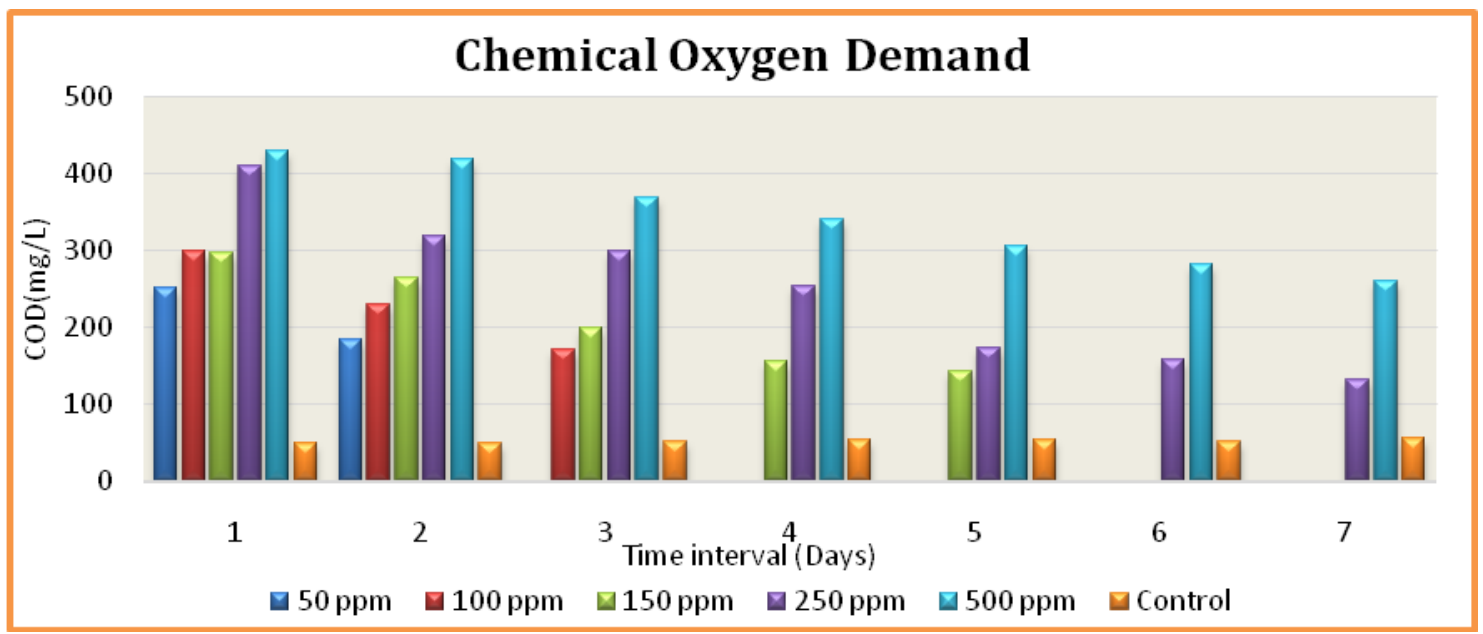

Clearly, the lag period at this concentration of toluene is very short. At $100 \mathrm{ppm}$ of toluene, degradation started within 1 day and $90 \%$ degradation occurred within $72 \mathrm{hr}$. Higher concentrations of Toluene like $250 \mathrm{ppm}$ and $500 \mathrm{ppm}$ were relatively more toxic for the microbial consortium and very little degradation was observed in $72 \mathrm{hrs} .500 \mathrm{ppm}$ showed only $51 \%$ even on completion of 7 days and was found to be inhibitory to the micro-organisms. The results of this study help to understand the microflora near the petrochemical industry (particularly toluene) and also determine the effectiveness of the microorganisms for the ability to degrade hazardous waste compound like toluene.

In conclusion, the current study is focused on isolation and characterization of indigenous bacteria from toluene effluent (sludge and contaminated sites) of Mahad, Maharashtra to assess the microbial metabolic potential towards bioremediation of contaminants present in those samples. Five isolates showed their ability to utilize petroleum hydrocarbon Toluene as sole source of carbon and energy as well as to withstand exposure to higher concentrations of stress during growth. Overall observation reflected the innate potential of indigenous microorganisms for bioremediation of contaminated sites with industrial waste.

\section{Acknowledgement}

Authors are grateful to University Grant Commission (UGC-SAP, UGC-Major Research Project) for rendering financial assistance.

\section{References}

Christofoletti, M., et al., 2010. BTEX biodegradation by bacteria from effluents of petroleum refinery. Sci. Total Environ., 408: 4334-40.

Harding, R.C., et al., 2003. Bioremediation of toluene-contaminated air using an external loop airlift bioreactor. J. Chem. Technol. Biotechnol., 78(4): 406-411.

Jacob, H., Jacob and Fawzi, I., Irshaid. 2015. Toluene Biodegradation by Novel Bacteria Isolated from Polluted Soil Surrounding Car Body Repair and Spray Painting Workshops. J. Environ. Protection, 6: 1417-1429.

Janbandhu, A. and Fulekar, M.H. 2011. Biodegradation of phenanthrene using adapted microbial consortium isolated from petrochemical contaminated 
environment. J. Hazardous Materials, 187(1): 1333-340.

Karamalidis, A.K., et al., 2010. Laboratory scale bioremediation of petroleumcontaminated soil by indigenous microorganisms and added Pseudomonas aeruginosa strain Spet. Biores. Technol., 101: 6545-6552.

Martino, C.D., et al., 2012. Isolation and characterization of benzene, toluene and xylene degrading Pseudomonas sp. selected as candidates for bioremediation. Int. Bio-deterioration \& Biodegradation, 67: 15-20.

Pérez, R.M., Cabrera, G., Gómez, J.M., Ábalos, A. and Cantero, D. 2010. Combined strategy for the precipitation of heavy metals and biodegradation of petroleum in industrial wastewaters. $J$. Hazardous Materials, 182(1-3): 896902.

Prenafeta-Bold'u1, F.X., et al., 2004. Bioremediation of BTEX hydrocarbons:
Effect of soil inoculation with the toluene-growing fungus Cladophialophora sp. strain T1. Biodegradation, 15: 59-65.

Qi, Y., et al., 2007. Isolation and Preliminary Characterization of a 3-Chlorobenzoate Degrading Bacteria. J. Environ. Sci., 19: 332-337.

Salleh, A.B., Ghazali, F.M., Zaliha, R.N., Rahman, A., Basri, M. 2003. Bioremediation of Petroleum Hydrocarbon Pollution. Indian $J$. Biotechnol., 2: 411-425.

Singh, Dipty, and M.H. Fulekar. 2009. Bioremediation of benzene, toluene and o-xylene by cow dung microbial consortium. J. Appl. Biosci., 14: 788795.

Singh, D., and Fulekar, M.H. 2009. Bioremediation of benzene, toluene and o-xylene by cow dung microbial consortium. J. Appl. Biosci., (14): 788795.

\section{How to cite this article:}

Fulekar, M.H., T.N. Godambe, Koul Sheetal and Nair Darshana. 2017. Bioremediation of Toluene using Microbial Consortium Obtained from Industrial Effluent. Int.J.Curr.Microbiol.App.Sci. 6(2): 552-558. doi: http://dx.doi.org/10.20546/ijcmas.2017.602.062 